\title{
Proportion of Dental Plaque Associated with Oral Hygiene Among the Students of A Dental College in Rajshahi, Bangladesh
}

\author{
A Awal ${ }^{1 *}$, T Akhter ${ }^{2}$ and T Akbar ${ }^{3}$ \\ ${ }^{1}$ Assistant Professor, Department of Public Health, Varendra University, Rajshahi, Bangladesh \\ ${ }^{2}$ Dental Surgeon, Doha, Qatar, Rajshahi, Bangladesh \\ ${ }^{3}$ Assistant Professor, Department of Paediatric Dentistry, Udayan Dental College, Rajshahi, Bangladesh \\ *Corresponding Author: A Awal, Assistant Professor Department of Public Health, Varendra University, Rajshahi, Bangladesh.
}

Received: October 15, 2019; Published: November 07, 2019

DOI: $10.31080 /$ ASDS.2019.03.0694

\begin{abstract}
This cross sectional type of descriptive study was conducted among the students of a Dental College, Rajshahi, Bangladesh with a view to estimate the proportion of dental plaque associated with oral hygiene. A total of 300 students were interviewed and examined which were selected purposively. The respondents were selected purposively. Data were collected from the respondents by face to face interview according to a partially structured questionnaire. The mean age of the respondents was 20.97 (SD \pm 1.76 ) years. Majority of the respondents (96.7\%) were under graduate students. The average monthly income of the family was BDT 24293.33 (SD \pm 6809.44 ). Most of the respondents $(60.7 \%)$ brushed their teeth twice a day and $72 \%$ of them brushed up and down and both surface of the teeth. About $88 \%$ used tooth paste and $96.3 \%$ used tooth brush. Among the respondents, $40.3 \%$ had no plaque, $43.7 \%$ had separate flecks at the cervical margin, $15.7 \%$ had plaque up to $1 \mathrm{~mm}$ and $0.3 \%$ had plaque wider than $1 \mathrm{~mm}$. In this study dental plaque had significant relationship with monthly family income $(\mathrm{p}<0.05)$, residence $(\mathrm{p}<0.001)$, frequency of tooth brushing ( $p<$ 0.001), technique of tooth brushing ( $<<0.001)$, materials used for tooth brushing $(p<0.001)$ and chewing habit ( $<<0.05)$. This study provided some important information which might help the concerned people to take appropriate measures and might be the basis for further in-depth study on this issue.
\end{abstract}

Keywords: Dental Plaque; Oral Hygiene Practices; Predisposing Factors; Bangladesh

\section{Introduction}

Dental plaque is a biofilm, usually a pale yellow thing that develops naturally on the teeth [1]. Like any biofilm, dental plaque is formed by colonizing bacteria trying to attach themselves to the tooth's smooth surface. It has been speculated that plaque forms part of the defense systems of the host by helping to prevent colonization of microorganisms that may be pathogenic. Oral cavity contains the only known anatomical aspect of the human body that does not have a regulated system of shedding surfaces: the teeth [2]. This allows microorganisms to adhere to the surface of teeth for long periods of time. These multiple species of bacteria become dental biofilm. Dental biofilm, more commonly referred to as dental plaque, is composed of about a thousand species of bacteria that take part in the complex ecosystems of the mouth [3]. The natural, non-frequent regulation of tooth shedding plays a large role in making dental biofilm the most diverse biofilm in the human body despite the relatively small size of the teeth. The human oral cavity is also called the human oral microbiome. This is because the human oral cavity can contain several environments at a given moment that could vary from tooth to tooth. Additionally it has been estimated that 25,000 species of bacteria reside in the mouth [4]. This is in contrast to the previously estimated $700+$ species. This is also in contrast to the previous estimate of more than 500 species as part of the dental biofilm [5]. These 1,000 species have 
the ability to change their environment through a series of biotic relationships. At first, the biofilm is soft enough to come off by using the fingernail. However, it starts to harden within 48 hours, and in about 10 days the plaque becomes dental calculus (tartar), which is hard and difficult to remove [6]. Dental plaque can give rise to dental caries (tooth decay) the localized destruction of the tissues of the tooth by acid produced from the bacterial degradation of fermentable sugars and periodontal problems such as gingivitis and chronic periodontitis [1]. Effective oral hygiene has been proposed as a key factor in the reduction of dental plaque colonization [7].

\section{Materials and Methods}

This cross sectional type of descriptive study was carried out among the students in a Dental College, Rajshahi, Bangladesh.
Sample size was 300 and that was selected purposively. All the students of a Dental College Rajshahi, Bnagladesh were included during the study period of 6 months. Dependent variable was used dental plaque in this study. As independent variables we used age, sex, monthly family income, frequency of tooth brushing, technique of tooth brushing, instruments and materials for brushing, mouth wash, smoking and chewing habit. Data were collected according to a duly pre-tested and partially structured questionnaire by face-to-face interview with the help of a key informant. The data were analyzed according to the objectives of the study by using SPSS/PC+ software (Version-21) computer program. Descriptive variables were explained with mean and standard deviation. Statistical significance was found by applying relevant statistical tests at appropriate probability level $(p=0.05$ or $p=0.01)$.

\section{Results}

\begin{tabular}{|c|c|c|c|c|c|}
\hline \multirow{2}{*}{ Variables } & \multicolumn{2}{|c|}{ Respondents } & \multirow{2}{*}{ Variables } & \multicolumn{2}{|c|}{ Respondents } \\
\hline & No. & $\%$ & & No. & $\%$ \\
\hline Age of the respondents: & & & Monthly family income & & \\
\hline $15-17$ years & 8 & 2.7 & Up to BDT 10000 & 6 & 2.0 \\
\hline $18-20$ years & 108 & 36.0 & BDT 10001-20000 & 95 & 31.7 \\
\hline 21-23 years & 174 & 58.0 & BDT $>20000$ & 199 & 66.3 \\
\hline $24+$ years & 10 & 3.3 & $X \pm S D=$ BDT $24293.33 \pm 6809.44$ & & \\
\hline$X \pm S D=20.97 \pm 1.76$ years & & & Technique of tooth brushing: & & \\
\hline Frequency of brushing: & & & Prevent tetanus & 78 & 26.0 \\
\hline Once daily & 108 & 36.0 & Do not know & 216 & 72.0 \\
\hline Twice daily & 182 & 60.7 & Prevent others disease & 6 & 2.0 \\
\hline More than 2 times daily & 4 & 1.3 & Materials for brushing & & \\
\hline Irregular & 6 & 2.0 & Tooth paste & 264 & 88.0 \\
\hline Instruments for brushing & & & Powder & 34 & 11.3 \\
\hline Tooth brush & 289 & 96.3 & Charcoal & 02 & 0.7 \\
\hline Wood stick & 11 & 3.7 & Dental plaque area measurement & & \\
\hline Use of mouth wash & & & No plaque & 121 & 40.3 \\
\hline Once daily & 161 & 53.7 & Separate flecks of plaque at the cervical mar- & 131 & 43.7 \\
\hline Twice daily & 22 & 7.3 & gin & & \\
\hline No & 117 & 39.0 & Plaque up to $1 \mathrm{~mm}$ at the cervical margin & 47 & 15.7 \\
\hline Plaque thickness measurement & & & Plaque wider than $1 \mathrm{~mm}$ but less than $1 / 3^{\text {rd }}$ of & 1 & 0.3 \\
\hline No plaque & 165 & 55.0 & surface & & \\
\hline Plaque at gingival margin & 104 & 34.7 & & & \\
\hline Thick plaque & 31 & 10.3 & & & \\
\hline
\end{tabular}

Table1: Distribution of the respondents by dental plaque and their socio-demographic characteristics. 


\begin{tabular}{|l|c|c|c|c|c|}
\hline \multirow{2}{*}{ Variables } & \multicolumn{3}{|c|}{ Dental plaque } & \multicolumn{2}{c|}{ Total } \\
\cline { 2 - 5 } & No plaque & Minimum plaque & Moderate to severe plaque & $111(37.0 \%)$ \\
\hline Low income & $30(29.7 \%)$ & $47(46.5 \%)$ & $24(23.8 \%)$ & $189(63.0 \%)$ \\
\hline High income & $91(45.7 \%)$ & $84(42.2 \%)$ & $24(12.1 \%)$ & $36(12.0 \%)$ & $P<0.001$ \\
\hline Rural & $5(13.9 \%)$ & $8(22.2 \%)$ & $23(63.9 \%)$ & $264(88.0 \%)$ \\
\hline Urban & $116(43.9 \%)$ & $123(46.6 \%)$ & $25(9.5 \%)$ & $108(36.0 \%)$ \\
\hline Once daily brushing & $26(24.1 \%)$ & $47(43.5 \%)$ & $35(32.4 \%)$ & $182(60.7 \%)$ \\
\hline Twice daily brushing & $93(51.1 \%)$ & $82(45.1 \%)$ & $7(3.8 \%)$ & $4(1.3 \%)$ \\
\hline More than 2 times daily & $2(50.0 \%)$ & $2(50.0 \%)$ & $0(0.0 \%)$ & $6(2.0 \%)$ \\
\hline Irregular & $0(0.0 \%)$ & $0(0.0 \%)$ & $6(100.0 \%)$ & $84(28.0 \%)$ \\
\hline To and fro technique of brushing & $7(8.3 \%)$ & $45(53.6 \%)$ & $32(38.1 \%)$ & P<0.001 \\
\hline Up \& down tech of brushing & $114(52.8 \%)$ & $86(39.8 \%)$ & $16(7.4 \%)$ & $216(72.0 \%)$ \\
\hline Tooth paste for brushing & $119(45.1 \%)$ & $116(43.9 \%)$ & $29(11.0 \%)$ & $264(88.0 \%)$ & $P<0.001$ \\
\hline Other materials for brushing & $2(5.6 \%)$ & $15(41.7 \%)$ & $19(52.8 \%)$ & $36(12.0 \%)$ \\
\hline No chewing habit & $108(44.1 \%)$ & $100(40.8 \%)$ & $37(15.1 \%)$ & $245(81.7 \%)$ \\
\hline Has chewing habit & $13(23.6 \%)$ & $31(56.4 \%)$ & $\mathrm{P}<0.05$ \\
\hline
\end{tabular}

Table 2: Relationship between dental plaque and other conditions.

\begin{tabular}{|c|c|c|c|c|c|}
\hline \multirow{3}{*}{$\begin{array}{l}\text { Variables } \\
\text { 15-17 years of age }\end{array}$} & \multicolumn{3}{|c|}{ Dental plaque thickness measurement } & \multirow{2}{*}{\multicolumn{2}{|c|}{ Total }} \\
\hline & \multirow{2}{*}{$\begin{array}{c}\begin{array}{c}\text { No plaque on } \\
\text { gingival margin }\end{array} \\
2(25.0 \%)\end{array}$} & \multirow{2}{*}{$\begin{array}{c}\begin{array}{c}\text { Plaque at gingi- } \\
\text { val margin }\end{array} \\
2(25.0 \%)\end{array}$} & \multirow{2}{*}{$\begin{array}{c}\text { Moderately thick plaque } \\
4(50.0 \%) \\
\end{array}$} & & \\
\hline & & & & $8(2.7 \%)$ & \multirow[t]{4}{*}{$\mathrm{P}<0.05$} \\
\hline $18-20$ years & $53(49.1 \%)$ & $44(40.7 \%)$ & $11(10.2 \%)$ & $108(36.0 \%)$ & \\
\hline $21-23$ years & $103(59.2 \%)$ & $57(32.8 \%)$ & $14(8.0 \%)$ & $174(58.0 \%)$ & \\
\hline $24+$ years & $7(70.0 \%)$ & $1(10.0 \%)$ & $2(20.0 \%)$ & $10(3.3 \%)$ & \\
\hline Rural & $7(19.4 \%)$ & $16(44.4 \%)$ & $13(36.1 \%)$ & $36(12.0 \%)$ & \multirow[t]{2}{*}{$\mathrm{P}<0.001$} \\
\hline Urban & $158(59.8 \%)$ & $88(33.3 \%)$ & $18(6.8 \%)$ & $264(88.0 \%)$ & \\
\hline Once daily brushing & $33(30.6 \%)$ & $53(49.1 \%)$ & $22(20.4 \%)$ & $108(36.0 \%)$ & \multirow{4}{*}{$\mathrm{P}<0.001$} \\
\hline Twice daily & $128(70.3 \%)$ & $51(28.0 \%)$ & $3(1.6 \%)$ & $182(60.7 \%)$ & \\
\hline More than 2 times daily & $4(100.0 \%)$ & $0(0.0 \%)$ & $0(0.0 \%)$ & $4(1.3 \%)$ & \\
\hline Irregular & $0(0.0 \%)$ & $0(0.0 \%)$ & $6(100.0 \%)$ & $6(2.0 \%)$ & \\
\hline $\begin{array}{l}\text { To and fro technique } \\
\text { fro brushing }\end{array}$ & $29(34.5 \%)$ & $34(40.5 \%)$ & $21(25.0 \%)$ & $84(28.0 \%)$ & \multirow[t]{2}{*}{$\mathrm{P}<0.001$} \\
\hline Up \& down & $136(63.0 \%)$ & $70(32.4 \%)$ & $10(4.6 \%)$ & $216(72.0 \%)$ & \\
\hline Using tooth brush & $165(57.1 \%)$ & $102(35.3 \%)$ & $22(7.6 \%)$ & $289(96.3 \%)$ & \multirow[t]{2}{*}{$\mathrm{P}<0.001$} \\
\hline Using wood stick & $0(0.0 \%)$ & $2(18.2 \%)$ & $9(52.8 \%)$ & $11(3.7 \%)$ & \\
\hline Mouth wash once daily & $101(62.7 \%)$ & $46(28.6 \%)$ & $14(8.7 \%)$ & $161(53.7 \%)$ & \multirow[t]{3}{*}{$\mathrm{P}<0.001$} \\
\hline Twice daily & $18(81.8 \%)$ & $4(18.2 \%)$ & $0(0.0 \%)$ & $22(7.3 \%)$ & \\
\hline No & $46(39.3 \%)$ & $54(46.2 \%)$ & $17(14.5 \%)$ & $117(39.0 \%)$ & \\
\hline
\end{tabular}

Table 3: Relationship between dental plaque thickness measurement and other conditions. 


\section{Discussion}

This study was carried out with a view to estimate the proportion of dental plaque associated with oral hygiene of the students of a dental college, Rajshahi, Bangladesh. The age range is mostly within young adult group of the population. Poor oral health was observed in this elderly population from South Brazil [2]. About monthly family income it was observed that majority $(66.3 \%)$ of the respondents had monthly family income of BDT more than 20000 followed by (31.7\%) of the respondents had monthly family income of BDT 10001 - 20000. Subjects with a low socio-economic status are significantly more likely than others to develop periodontal disease [3]. Regarding frequency of tooth brushing $(60.7 \%)$ used to brush teeth twice daily, most of the respondents $(72.0 \%)$ used to brush both surface up and down of teeth, majority (96.3\%) used tooth brush as an instrument of brushing. In the multivariable model, the risk of fissure development was two times higher with medium hard compared with soft toothbrushes [4]. Figure 1 showed that most of the respondents (88.0\%) belonged to rural area. There was a strong association between cigarette smoking and risk of periodontitis among older Thai adults [5]. It was evident that there was a significant relationship between income of the respondents and dental plaque $(\mathrm{p}<0.05)$. Socio-demographic disparities accounted for most of the burden of disease and treatment needs [6]. Subjects with a low socio-economic status are significantly more likely than others to develop periodontal disease [7].

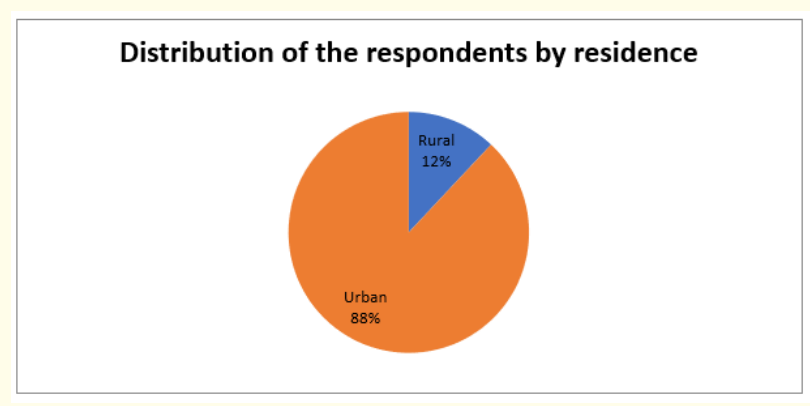

Figure 1: Distribution of the respondents by residence.

\section{Conclusion}

This study has provided an insight into the periodontal status and predisposing factors for periodontal diseases of selected groups over eight months. As such they provide valuable information to help plan a full national study, should resources be made available for such a study. The respondents were dental students so, they would have to know more about the oral hygiene instructions.

\section{Bibliography}

1. Gao XJ., et al. "A study of oral health condition in individuals with no oral hygiene and its association with plaque acidogenesis". Chinese Journal of Dental Research 3.2 (2000): 44-48.

2. Gaio Ej., et al. "Oral health status in elders from South Brazil: a population-based study”. Gerodontology 29.3 (2012): 214-223.

3. Rossete Melo R., et al. "Sociodemographic, biological and behavioural risk factors associated with incidence of dental caries in school children's first permanent molars: a 3-year follow-up study". European Journal of Paediatric Dentistry 14.1 (2013): 8-12.

4. Greggianin BF, et al. "The incidence of gingival fissures associated with tooth brushing: crossover 28-day randomized trial". Journal of Clinical Periodontology 40.4 (2013): 319-326.

5. Torrungruang K., et al. "The effect of cigarette smoking on the severity of periodontal disease among older Thai adults". Journal of Periodontology 76.4 (2005): 566-572.

6. Gaio Ej., et al. "Oral health status in elders from South Brazil: a population-based study". Gerodontology 29.3 (2012): 214-223.

7. Javed F., et al. "Dental caries etiology, pathology and prevention". The American Journal of the Medical Sciences 346.4 (2013): 273-278.

\section{Volume 3 Issue 12 December 2019 (C) All rights are reserved by A Awal., et al.}

